\title{
Section Editorial
}

\section{Implementing the urban village concept: lessons from practice}

This special section of Urban Design International is concerned with exploring the lessons that can be learnt from attempts to implement the Urban Village concept in the UK. Back in the early 1990s urban villages were everywhere, and they were rightly regarded as the UK's contribution to thinking about what has become known as new urbanism. In parallel with debates going on in the US in the Congress for New Urbanism, so in the UK the Urban Village Forum went out and sold its ideas about a form of development which would result in more balanced communities, as well as a form of development that would enhance community relations, bolster local services, reduce the need or the desire to travel and also create a pattern of development with a far greater concern for a sense of place.

The concept combines a number of common planning discourses including a concern for urban design and sustainable urban forms along with a rigorous return to concepts used in neighbourhood planning and a celebration of polycentrism as a desirable structure for urban areas. Essentially the mantra was: let us plan our cities to be a combination of neighbourhoods, each with the physical, social and economic characteristics of a village; a place with a central square which is the focus of community life, where you know your neighbours, use the local shops and your social life is focused around the local institutions or facilities. Subsequent to the formulation of the concept, the Urban Village Forum sought the mechanisms for its implementation, starting out with a desire to build a free standing scheme on a Greenfield site, and then failing that, encouraging the use of the concept in urban renewal schemes.

This section explores a number of urban village schemes to consider how and why the urban village concept became so prevalent in the UK, to explore its manifestations, as well as also to consider if there is an empirical basis for the assertions presented in the Urban Village Forum's own publications.

Mike Biddulph's paper defines the urban village concept and then explores both how and why the concept has been adopted within an urban renewal context, as well as also considering if the concept was really appropriate. The context is an established and deprived community in Merseyside where the urban village idea was introduced as a mechanism for securing renewal funding. The case study illustrates how the adoption of the concept within the locality remained largely confined to professional discourse. The paper concludes that urban renewal contexts do not necessarily provide adequate conditions for such a concept to be successful, while empirical work also highlighted that the concept was contrary to local aspirations.

Bridget Franklin explores the 'urban village' scheme in Bordesley, Birmingham, a run down inner city community just to the east of the city centre. The paper investigates the significance of adopting the urban village designation in this case, and the extent to which outcomes could be described as urban-village-like. In conclusion, it is suggested that 'success' and 'failure' cannot be assessed, and that they are subjective and contextual notions that need to be predicated on the characteristics of the here and now rather than on the objective, standardised and decontextualised criteria that appear in the Urban Village Forum publications. Tellingly she argues in the conclusion: 'Those on the outside, both in space and time, use objective, normative and decontextualised criteria. Those on the inside... have a more subjective and contextual perspective, based on a meaningful relationship with a real, rather than an imagined, locality.'

Malcolm Tait looks at the extent to which the urban village scheme of West Silvertown in London Docklands resulted in a localised, selfsufficient and integrated community, as its planning vision espoused. His empirical work found a mixed picture, highlighting different patterns of spatial activity and discrete social networks instead of the more homogeneous pattern outlined in the vision for West Silvertown. His work has led him to conclude that the spatial organisation of objects, such as housing types or shops does not have a predictable effect on social activity, and that a more nuanced understanding of spatial activity is necessary, one which takes into account economic and social relations as well 
as physical design and perhaps does not rely on uniform models of development similar to that espoused by the Urban Villages Forum.

Tim Brindley takes a step back from specific schemes and considers how debates about sustainable patterns of urban development often include an implicit set of social objectives or aspirations that are rarely spelt out in detail but which are seen in frequent allusions to the social concepts of 'village' and 'community' life. He explores three influential proposals for how sustainable urban development might generally be delivered and argues that the aspirations run counter to social trends such as increasing social and economic differentiation and segregation, while they also deny the emergence of a postmodern culture, with increasingly fragmented patterns of social relations and arbitrary lifestyle choices. He argues that traditional communities have long since given way to preferred modern and post-modern forms of community life, where local social bonds and place attachments are weaker or non-existent, but place identity plays an important part in locational choices. Interestingly he concludes that urban village schemes may be successful where differentiated consumers buy into the development vision as a life style choice, although he queries their general relevance or desirability.

Michelle Thompson-Fawcett presents the results of her research into resident observations of life in Poundbury, Dorchester. She finds that feelings are mixed, but that there is a balanced community, that among property owners a feeling of community has been achieved, and that a high-quality environment has also been realised. Essentially there has been a high level of 'buy-in' to the scheme's ambitions. Having said this there is also some evidence that residents are modifying the scheme and its management to match their aspirations, highlighting how use of the public realm can remain contested and firmly beyond the ability of planners and designers to influence.

Drawing together the findings of these papers a number of more generalised lessons seem to emerge. Firstly, that many of the social claims made on behalf of the concept are as yet unproven, and that within schemes more general trends of social differentiation and association still prevail. Put simply, there is no evidence that building a particular form of development will create social integration or a coherent sense of community.

Secondly, in terms of schemes where urban design had been a concern, many of the residents appreciated the qualities of the resulting environment, although in Poundbury at least some of the residents have been modifying the original aspirations, reflecting how designs that aim to be inclusive can be subverted through management and social pressure.

Thirdly, it was clear that the urban village idea is largely limited to a professional discourse, and that its universal relevance is also unproven. There was clear evidence in both Merseyside and Bordesley that the concept was at best ignored and at worst contested by local people whose priorities lay elsewhere. This was most profound in the forms of meaning associated with normative planning concepts, for example, the way planners would consider a degree of self-containment as promoting identity and intimacy, while for residents of a deprived neighbourhood, it would mean stigmatisation, a lack of opportunity and choice.

Fourthly, it was found that despite the vision to create some degree of greater self-sufficiency in terms of both work and services, that all of the schemes remained reliant on their wider context and that often this reliance was as a result of positive choices made by mobile citizens. Such trends do discriminate against those people who are or choose to be less mobile, but certainly it is clear that in none of the cases were the schemes able to overcome more general decentralising trends.

Finally, in being translated from concept to practice, the urban village idea is strongly influenced and also contested by the professional actors and agents who seek its delivery. In a renewal context, for example, the involvement of English Partnerships, in providing funding in support of the concept, certainly influenced the extent to which it was regarded as relevant. To this end, the substance of the concept has not always been that important, and planners have not actually be thinking too hard about whether an urban village would result. Instead their approach would be to consider how they could align their context's own circumstances to the concerns of the funding agency to gain access to 
resources. Through such a process the concept has essentially been unravelled, as it has been confronted by the contradictory circumstances it has met.

As a result of this work, we can determine that what we are left with are a number of schemes of varying quality. A lot of time and good intentions have been committed to translating the urban village vision into something appropriate for a given context, and some of the resulting schemes look attractive and provide apparently good living environments, but as yet most of them seem to be lived in pretty much like any other bit of town, or dare it be said ... housing estate.

Mike Biddulph Cardiff University 